\title{
Healthcare Fragmentation and Incident Acute Coronary Heart Disease Events: a Cohort Study
}

\author{
Lisa M. Kern, $M D, M P H^{7}$ (D), Mangala Rajan, $M B A^{7}$, Joanna Bryan Ringel, $M P H^{7}$, \\ Lisandro D. Colantonio, MD, $P h D^{2}$, Paul M. Muntner, $P h D^{2}$, \\ Lawrence P. Casalino, MD, $P h D^{\prime}$, Michael Pesko, $P h D^{3}$, Evgeniya Reshetnyak, $P h D^{\prime}$, \\ Laura C. Pinheiro, $P h D^{7}$, and Monika M. Safford, $M D^{7}$ \\ 'Weill Cornell Medicine New York, NY, USA; ${ }^{2}$ University of Alabama at Birmingham Birmingham, AL, USA; ${ }^{3}$ Georgia State University Atlanta, GA, USA.
}

\begin{abstract}
BACKGROUND: Highly fragmented ambulatory care (i.e., care spread across many providers without a dominant provider) has been associated with excess tests, procedures, emergency department visits, and hospitalizations. Whether fragmented care is associated with worse health outcomes, or whether any association varies with health status, is unclear.
\end{abstract}

OBJECTIVE: To determine whether fragmented care is associated with the risk of incident coronary heart disease (CHD) events, overall and stratified by self-rated general health.

DESIGN AND PARTICIPANTS: We conducted a secondary analysis of the nationwide prospective Reasons for Geographic and Racial Differences in Stroke (REGARDS) cohort study (2003-2016). We included participants who were $\geq 65$ years old, had linked Medicare fee-for-service claims, and had no history of CHD $(N=10,556)$.

MAIN MEASURES: We measured fragmentation with the reversed Bice-Boxerman Index. We used Cox proportional hazards models to determine the association between fragmentation as a time-varying exposure and adjudicated incident CHD events in the 3 months following each exposure period.

KEY RESULTS: The mean age was 70 years; 57\% were women, and 34\% were African-American. Over 11.8 years of follow-up, 569 participants had CHD events. Overall, the adjusted hazard ratio (HR) for the association between high fragmentation and incident CHD events was 1.14 (95\% confidence interval (CI) $0.92,1.39$ ). Among those with very good or good self-rated health, high fragmentation was associated with an increased hazard of CHD events (adjusted HR 1.35; 95\% CI 1.06, 1.73; $p=0.01$ ). Among those with fair or poor self-rated health, high fragmentation was associated with a trend toward a decreased hazard of CHD events (adjusted HR 0.54; 95\% CI $0.29,1.01 ; p=0.052$ ). There was no association among those with excellent self-rated health.

CONCLUSION: High fragmentation was associated with an increased independent risk of incident CHD events among those with very good or good self-rated health.

Supplementary information The online version of this article (https:// doi.org/10.1007/s11606-020-06305-z) contains supplementary material, which is available to authorized users.

Received January 17, 2020

Accepted October 7, 2020

Published online November 2, 2020
$\mathrm{J}$ Gen Intern Med 36(2):422-9

DOI: $10.1007 / \mathrm{s} 11606-020-06305-\mathrm{Z}$

(C) Society of General Internal Medicine 2020

\section{INTRODUCTION}

Receiving ambulatory care from multiple providers is common. ${ }^{1}$ For example, $50 \%$ of Medicare beneficiaries nationally see 7 or more different physicians each year. ${ }^{1}$ This may be clinically appropriate, but it creates challenges, as providers often do not communicate with each other regarding their common patients. ${ }^{2,3}$ As a result, clinically relevant information, such as the results of tests ordered by another physician, is missing in 1 out of every 7 visits. ${ }^{4}$ More fragmented ambulatory care (that is, care spread across many providers without a dominant provider) has been associated with more testing, ${ }^{5}$ more procedures, ${ }^{6}$ more emergency department visits, ${ }^{7-9}$ and more hospitalizations, ${ }^{7,10}$ compared to less fragmented care. However, the relationship between fragmented ambulatory care and health outcomes is unclear. ${ }^{11}$

We previously found that the association between fragmented ambulatory care and subsequent healthcare utilization varies with patients' health status. ${ }^{5,12} \mathrm{We}$ hypothesize that the association between fragmented ambulatory care and health outcomes might also vary with health status. Healthy people might be able to see multiple providers without experiencing harm from gaps in communication, whereas sicker individuals might be more vulnerable to harm.

Prior to a myocardial infarction (MI), many patients have cardiovascular risk factors, ${ }^{13}$ such as hypertension and diabetes, which are often managed by multiple ambulatory providers (primary care physicians, cardiologists, endocrinologists, and others). ${ }^{14}$ We sought to determine whether more fragmented ambulatory care is associated with an increased risk of incident coronary heart disease (CHD) events, overall and by health status.

\section{METHODS}

\section{Study Design, Population, and Data Sources}

We conducted an ancillary study to the nationwide, prospective Reasons for Geographic and Racial Differences in Stroke 
(REGARDS) cohort study, using data from 2003 to $2016 .{ }^{15}$ Institutional review boards of the participating institutions approved the protocol. All participants provided written informed consent.

Between 2003 and 2007, 30,239 community-dwelling African-American and white adults $\geq 45$ years old were enrolled in the REGARDS study, with oversampling of AfricanAmerican adults and individuals living in the Southeastern U.S. ${ }^{15}$ Baseline data collection involved computer-assisted telephone interviews (CATI) and in-home visits with a physical examination, blood test, urine test, electrocardiogram (ECG), and medication inventory. Participants or their proxies are contacted by telephone every 6 months to detect study endpoints. The report of a potential event triggers adjudication, which involves an expert review of medical records, death certificates, proxy interviews, autopsy reports, the Social Security Death Index, and the National Death Index (NDI). ${ }^{16}$

For this study, we used REGARDS study baseline data, REGARDS-adjudicated events, and REGARDS-linked Medicare claims data. ${ }^{17}$

\section{Variables}

Exposure. We used Medicare claims to identify ambulatory visits, which were defined using a modified National Committee for Quality Assurance (NQCA) definition ${ }^{18}$ restricted to Clinical Procedure Terminology (CPT) codes for in-person, evaluation-and-management visits for adults in an office setting. ${ }^{5}$ The NCQA definition of ambulatory visits does not include emergency department visits. We calculated fragmentation scores for each participant, using the previously validated ${ }^{7,10}$ Bice-Boxerman Index (BBI, Appendix 1). ${ }^{19}$ This index was originally labeled as a measure of "continuity," but - as its originators intended - it actually measures more than consistency of care with a single provider. It captures both "dispersion" (the spread of visits across providers) and "density" (the relative share of visits by each provider). ${ }^{20}$ Values of the original BBI range from 0 (least continuity, or most fragmentation) to 1 (most continuity, or least fragmentation). Patients receive a raw score of 0 if each ambulatory visit is with a different provider and a raw score of 1 if all visits are with the same provider. Other patterns of visits and providers receive intermediate scores; patterns with high dispersion (many providers) and low density (a relatively low proportion of visits by each provider) receive worse scores (indicating more fragmentation) than patterns with low dispersion and high density. To facilitate interpretation, we reversed the scores, calculating 1 minus BBI, so that higher scores reflect more fragmentation. ${ }^{5,9,12}$

Outcome. An incident CHD event was defined as a definite or probable fatal or non-fatal MI or CHD death. Adjudication of MI followed national guidelines and was based on a clinical presentation suggestive of ischemia; cardiac biomarkers, usually troponin, exhibiting a rising and/or falling pattern to at least twice the upper limit of normal over at least $6 \mathrm{~h}$; or imaging suggestive of acute ischemia. ${ }^{16,21,22}$ Adjudication of CHD death included sudden cardiac death and deaths for which insufficient information could be gathered to adjudicate an MI but where the NDI cause of death was an acute coronary event. We used events adjudicated through December 31, 2016.

Baseline Covariates. Demographics included self-reported age, gender, race, marital status, educational attainment, and annual household income; geographic region from baseline contact information; and rural/urban setting using rural/urban commuting area codes. ${ }^{23}$ Medical conditions included hypertension (self-reported use of anti-hypertensive medication, systolic blood pressure $\geq 140 \mathrm{mmHg}$, or diastolic blood pressure $\geq 90 \mathrm{mmHg}$ from the in-home visit), hyperlipidemia (use of lipid-lowering medication, total cholesterol $\geq 240 \mathrm{mg} / \mathrm{dL}$, low-density lipoprotein cholesterol (LDL) $\geq 160 \mathrm{mg} / \mathrm{dL}$, or high-density lipoprotein (HDL) cholesterol $\leq 40 \mathrm{mg} / \mathrm{dL}$ from the in-home visit), diabetes (fasting glucose $\geq 126 \mathrm{mg} / \mathrm{dL}$ or non-fasting glucose $\geq 200 \mathrm{mg} / \mathrm{dL}$ from the in-home visit, or self-reported use of oral glucose-lowering medication or insulin), atrial fibrillation (self-reported or present on the study ECG at baseline), and stroke (self-reported). Medications included the total number of prescription medications taken in the past 2 weeks by medication inventory, self-reported use of anti-hypertensive medication and insulin from the CATI, and statin use from the medication inventory. Health behaviors were self-reported and included smoking status, alcohol consumption, ${ }^{24}$ and exercise frequency. Psychosocial variables included whether a participant reported being the primary caretaker for another individual and whether he or she saw any close friends or relatives in the past month. Depressive symptoms were defined as Center for Epidemiologic Studies Depression Scale (CES-D) scores $\geq 4 .^{25}$ Physiological variables included body mass index (BMI); systolic blood pressure; total, LDL, and HDL cholesterol; glucose; estimated glomerular filtration rate (eGFR); ${ }^{26}$ urinary albumin-to-creatinine ratio (ACR), ${ }^{27}$ and high-sensitivity C-reactive protein. Selfrated health was assessed using self-rated general health (SF1) from the 12-Item Short Form Health Survey (SF-12). ${ }^{28-31}$

\section{Statistical Analysis}

We included participants $\geq 65$ years old whose REGARDS data were linked to Medicare claims at any time during the study period, allowing for staggered entry as younger participants aged into Medicare when they turned $65 .{ }^{32}$ We excluded participants who (1) were eligible for Medicare on the basis of end-stage renal disease, (2) had fewer than 12 months of continuous Medicare fee-for-service coverage or had Medicare managed care, (3) were lost to follow-up prior to entry into this ancillary study, (4) had $\leq 3$ ambulatory visits in the first year of observation, ${ }^{10}$ (5) had evidence of CHD (selfreport of MI or coronary revascularization, ECG, or adjudicated MI) prior to or during the first year of observation, or (6) had a missing value for self-rated health. 
We used descriptive statistics to characterize the sample at baseline and summarize ambulatory care utilization in the first year of observation. We used the 75th percentile fragmentation score from the first year of observation $(0.85)$ to dichotomize fragmentation into high $(\geq 0.85)$ and low $(<0.85)$. This approach was informed by our previous studies ${ }^{5,12}$ and by the goal of identifying individuals who have such high scores that they might benefit from future interventions if high fragmentation is found to be associated with increased CHD risk. To compare differences between participants with and without high fragmentation, we used Wilcoxon rank-sum tests, $t$ tests, and chi-square tests.

Because fragmentation can change over time, we treated fragmentation as a time-dependent exposure. ${ }^{10,12,33}$ Because the effects of fragmentation are hypothesized to occur relatively quickly (for example, if different doctors unknowingly prescribe drugs that interact, the subsequent drug-drug interaction would be an acute event), previous studies have measured the occurrence of outcomes (e.g., ED visits and hospitalizations) in the 1 month following exposure to ambulatory fragmentation. ${ }^{12,33}$ For this study of CHD events, we lengthened the period of observation for outcomes to 3 months following the exposure to ambulatory fragmentation and conducted a sensitivity analysis lengthening it further to 6 months. We did not lengthen the outcome period beyond 6 months, because any exposure period and its corresponding outcome period are mutually exclusive; thus, the longer the outcome period, the more that ambulatory utilization (from the outcome period) is inadvertently omitted from the calculation of the exposure.

Observation for each participant began after the in-home visit with the first 12-month period for which there was continuous Medicare fee-for-service coverage, starting with calendar year 2004. For each participant, we calculated a fragmentation score for the first 12 months of his or her observation period and then determined whether a CHD event occurred in the 3 months immediately following the exposure period (months 13-15). If no event occurred, we moved the window of observation forward by 3 months, measuring fragmentation in months $4-15$ and any event in months $16-18$, and so on (Appendix 2). If the number of visits in any 12month exposure period fell below 4 , we carried forward the last fragmentation score based on $\geq 4$ visits. ${ }^{10}$ Observation continued until an outcome or censoring occurred; censoring occurred when a participant died of non-CHD causes, no longer had Medicare fee-for-service coverage, dropped out of the REGARDS study, or reached December 31, 2016. We used Poisson regression to estimate absolute adjusted rates of CHD events. We used Cox proportional hazards models to estimate unadjusted and adjusted hazard ratios. ${ }^{34-36}$ Using Schoenfeld residuals, we determined that the assumption of proportional hazards was met. We included in multivariate models those covariates that had a bivariate association with fragmentation $(p<0.10)$, except for gender, race, and region, which were automatically included to account for the sampling frame. If two variables had bivariate $p$ values $<0.10$, but one was embedded in the definition of another (e.g., use of antihypertensive medication was embedded in the definition of hypertension), we only adjusted for the broader variable to avoid collinearity.

We conducted a formal test of interaction between fragmentation and self-rated health category (excellent, very good or good, fair or poor) and stratified models if the interaction term was statistically significant. We used three groupings of selfrated health in order to detect any differences across subgroups, while maximizing statistical power.

We conducted six separate sensitivity analyses. First, we used the same covariates as in the base case analysis with multiple imputation to handle missing covariates. ${ }^{37}$ The most frequently missing variable was $\mathrm{C}$-reactive protein (missing for 6\%); $85 \%$ of the sample was included in the complete case analysis. Second, we restricted the analysis to those $\geq 65$ years old at baseline, excluding those who aged into Medicare over the study period. Third, we changed the time period for outcomes from 3 to 6 months immediately following each exposure period. Fourth, we used all unique covariates (not including variables embedded in the definitions of other variables), instead of selecting covariates based on bivariate $p$ values, with a complete case approach. Fifth, we used all unique covariates, with multiple imputation to handle missing covariate values. Sixth, we stratified the sample into 5 self-rated health groups instead of 3 .

Analyses were conducted with SAS (version 9.4, Cary, NC) and Stata (version 14, StataCorp, College Station, TX). Multivariate $p$ values $<0.05$ were considered statistically significant.

\section{RESULTS}

\section{Sample Characteristics}

Of the REGARDS study participants, 10,566 met the inclusion criteria (Appendix 3). The mean age of participants was 70 years (Table 1, Appendix 4). More than half of participants $(57 \%)$ were women, and $34 \%$ were African-American. Twothirds $(66 \%)$ had very good or good self-rated health. By design, one-fourth (25\%) had high fragmentation. Differences in participant characteristics between those with high vs. low fragmentation in the first year of observation are shown in Table 1. Participant characteristics stratified by self-rated health are shown in Appendix 5.

\section{Ambulatory Utilization}

Those with high fragmentation had an average of 10.7 visits across 6.3 providers, an average of $29 \%$ of visits with the most frequently seen provider, and an average fragmentation score of 0.91 ; by contrast, those with low fragmentation had an average of 8.8 visits across 3.5 providers, an average of $58 \%$ of visits with the most frequently seen provider, and an average fragmentation score of 0.63 (Table $2, p<0.001$ for each comparison). 
Table 1 Baseline Characteristics, Overall and Stratified by Fragmentation Score in the First Year of Observation

\begin{tabular}{|c|c|c|c|c|}
\hline Characteristic & Overall $(N=10,556)$ & $\begin{array}{l}\text { Low fragmentation } \\
\text { during first year } \\
\text { of observation }(N=7889)\end{array}$ & $\begin{array}{l}\text { High fragmentation } \\
\text { during first year } \\
\text { of observation }(N=2667)\end{array}$ & $p$ value \\
\hline \multicolumn{5}{|l|}{ Demographic characteristics } \\
\hline Age, years, mean (SD) & $70.3(5.9)$ & $70.4(5.9)$ & $69.9(5.8)$ & $<0.001$ \\
\hline Gender, female, $N(\%)$ & $6007(57)$ & $4453(56)$ & $1554(58)$ & 0.10 \\
\hline Race, white, $N(\%)$ & $6968(66)$ & $5013(64)$ & $1955(73)$ & $<0.001$ \\
\hline Marital status, married, $N(\%)$ & $6195(59)$ & $4548(58)$ & $1647(62)$ & $<0.001$ \\
\hline Education, college graduate, $N(\%)$ & $3850(36)$ & $2723(35)$ & $1127(42)$ & $<0.001$ \\
\hline Annual household income, $<\$ 35,000, N(\%)$ & $4541(43)$ & $3540(45)$ & $1001(38)$ & $<0.001$ \\
\hline \multicolumn{5}{|l|}{ Geographic region, $N(\%)$} \\
\hline Stroke belt ${ }^{\mathrm{a}}$ & $3876(37)$ & $2858(36)$ & $1018(38)$ & 0.04 \\
\hline Stroke buckle ${ }^{b}$ & $2434(23)$ & $1865(24)$ & $569(21)$ & \\
\hline Neither stroke belt nor stroke buckle & $4246(40)$ & $3166(40)$ & $1080(40)$ & \\
\hline \multirow{2}{*}{\multicolumn{5}{|c|}{ Medical conditions ${ }^{c}$}} \\
\hline & & & & \\
\hline Hypertension, $N(\%)$ & $6331(60)$ & $4866(62)$ & $1465(55)$ & $<0.001$ \\
\hline Hyperlipidemia, $N(\%)$ & $5966(59)$ & $4524(59)$ & $1442(56)$ & 0.01 \\
\hline Diabetes, $N(\%)$ & $2030(20)$ & $1576(21)$ & $454(18)$ & $<0.001$ \\
\hline Atrial fibrillation, $N(\%)$ & $774(7)$ & $547(7)$ & $227(9)$ & 0.01 \\
\hline Stroke, $N(\%)$ & $609(6)$ & $470(6)$ & $139(5)$ & 0.15 \\
\hline \multicolumn{5}{|l|}{ Medications } \\
\hline Number of medications, median (IQR) & $5(3,8)$ & $5(3,8)$ & $6(3,9)$ & $<0.001$ \\
\hline Anti-hypertensive medication, $N(\%)$ & $5471(54)$ & $4219(55)$ & $1252(48)$ & $<0.001$ \\
\hline Insulin use, $N(\%)$ & $476(5)$ & $354(5)$ & $122(5)$ & 0.87 \\
\hline Statin use, $N(\%)$ & $3151(30)$ & $2356(30)$ & $795(30)$ & 0.96 \\
\hline \multicolumn{5}{|l|}{ Health behaviors } \\
\hline Current smoker, $N(\%)$ & $1130(11)$ & $890(11)$ & $240(9)$ & $<0.001$ \\
\hline Alcohol use, none, $N(\%)$ & $6629(64)$ & $5050(65)$ & $1579(60)$ & $<0.001$ \\
\hline Exercise frequency, 0 times per week, $N(\%)$ & $3560(34)$ & $2675(34)$ & $885(34)$ & 0.72 \\
\hline \multicolumn{5}{|l|}{ Psychosocial variables } \\
\hline \multirow{2}{*}{\multicolumn{5}{|c|}{ with a chronic illness or disability, $N(\%)$}} \\
\hline & & & & \\
\hline Lack of social support, $N(\%)$ & $429(4)$ & $302(4)$ & $127(5)$ & 0.04 \\
\hline Depressive symptoms, $N(\%)$ & $588(6)$ & $439(6)$ & $149(6)$ & 0.97 \\
\hline \multicolumn{5}{|l|}{ Physiological variables } \\
\hline Body mass index, $\mathrm{kg} / \mathrm{m}^{2}$, mean $(\mathrm{SD})$ & $28.8(5.8)$ & $28.9(5.9)$ & $28.6(5.7)$ & 0.01 \\
\hline Systolic blood pressure, $\mathrm{mmHg}$, mean (SD) & $128.5(16.3)$ & $129.0(16.4)$ & $127.1(15.9)$ & $<0.001$ \\
\hline Total cholesterol, $\mathrm{mg} / \mathrm{dL}$, mean $(\mathrm{SD})$ & $193.5(38.9)$ & $194.0(39.3)$ & $192.1(37.7)$ & 0.03 \\
\hline $\begin{array}{l}\text { Low-density lipoprotein cholesterol, } \\
\mathrm{mg} / \mathrm{dL} \text {, mean (SD) }\end{array}$ & $114.4(33.9)$ & $115.1(34.3)$ & $112.5(32.4)$ & $<0.001$ \\
\hline $\begin{array}{l}\text { High-density lipoprotein cholesterol, } \\
\mathrm{mg} / \mathrm{dL} \text {, mean (SD) }\end{array}$ & $52.7(16.4)$ & $52.4(16.3)$ & $53.6(16.7)$ & 0.002 \\
\hline Glucose, mg/dL, mean (SD) & $102.6(32.3)$ & $103.1(33.0)$ & $101.1(30.2)$ & 0.01 \\
\hline $\begin{array}{l}\text { Estimated glomerular filtration rate, } \\
\mathrm{mL} / \mathrm{min} / 1.73 \mathrm{~m}^{2}, \text { mean }(\mathrm{SD})\end{array}$ & $81.9(18.3)$ & $81.8(18.5)$ & $82.2(17.7)$ & 0.34 \\
\hline Urinary albumin-to-creatinine ratio, & $7.6(4.8,15.8)$ & $7.7(4.9,16.1)$ & $7.4(4.7,14.6)$ & 0.02 \\
\hline $\begin{array}{l}\mathrm{mg} / \mathrm{g}, \text { median }(\mathrm{IQR}) \\
\mathrm{C} \text {-reactive protein, } \mathrm{mg} / \mathrm{L} \text {, median (IQR) }\end{array}$ & $21\left(\begin{array}{lll}0 & 9 & 4\end{array}\right)$ & $20(1048)$ & & 005 \\
\hline \multicolumn{5}{|l|}{ Self-rated health } \\
\hline \multicolumn{5}{|l|}{ Self-rated general health (SF-1), $N(\%)$} \\
\hline Excellent & 1959 (19) & $1423(18)$ & $536(20)$ & 0.11 \\
\hline Very good & $3428(32)$ & $2564(33)$ & $864(32)$ & \\
\hline Good & $3606(34)$ & $2721(34)$ & $885(33)$ & \\
\hline Fair & $1315(12)$ & $986(12)$ & $329(12)$ & \\
\hline Poor & $248(2)$ & $195(2)$ & $53(2)$ & \\
\hline
\end{tabular}

Missing data: education $(N=5)$, hypertension $(N=27)$, hyperlipidemia $(N=382)$, diabetes $(N=370)$, atrial fibrillation $(N=203)$, body mass index $(N=57)$, number of medications $(N=8)$, smoking status $(N=38)$, alcohol use $(N=187)$, social support $(N=248)$, urinary albumin-to-creatinine ratio $(N=443)$, and $C$-reactive protein $(N=616)$. Percentages may not sum to 100 due to rounding. See Appendix 3 for a longer version of this table with all categories of each variable shown

IQR interquartile range, SF short-form survey ${ }^{31}$

${ }^{a}$ Stroke Belt $=$ North Carolina, South Carolina, Georgia, Tennessee, Mississippi, Alabama, Louisiana, and Arkansas (except for 153 coastal counties that constitute the Stroke Buckle) ${ }^{15}$

${ }^{b}$ Stroke Buckle = 153 coastal counties in North Carolina, South Carolina, and Georgia ${ }^{15,38}$

'See "METHODS" section for detailed definitions of variables

Within each self-rated health group, those with high fragmentation had more visits, more providers, a lower proportion of visits with the most frequently seen provider, and higher fragmentation scores than those with low fragmentation $(p<0.001$ for each comparison).

\section{CHD Events}

Participants were followed up for up to 11.8 years (median 5.5 years) (Table 3). Overall, 569 participants $(5.4 \%)$ experienced an acute incident CHD event, equivalent to an 
Table 2 Ambulatory Utilization During the First Year of Observation, Overall and Stratified by Fragmentation Score and by Self-Rated Health

\begin{tabular}{|c|c|c|c|c|c|c|c|c|c|c|c|c|}
\hline & \multirow{2}{*}{\multicolumn{3}{|c|}{ Overall }} & \multicolumn{9}{|c|}{ Self-rated health } \\
\hline & & & & \multicolumn{3}{|c|}{ Excellent } & \multicolumn{3}{|c|}{ Very good or good } & \multicolumn{3}{|c|}{ Fair or poor } \\
\hline & Total & $\begin{array}{l}\text { Low } \\
\text { rBBI } \\
(<0.85)\end{array}$ & $\begin{array}{l}\text { High } \\
\text { rBBI } \\
(\geq 0.85)\end{array}$ & Total & $\begin{array}{l}\text { Low } \\
\text { rBBI } \\
(<0.85)\end{array}$ & $\begin{array}{l}\text { High } \\
\text { rBBI } \\
(\geq 0.85)\end{array}$ & Total & $\begin{array}{l}\text { Low } \\
\text { rBBI } \\
(<0.85)\end{array}$ & $\begin{array}{l}\text { High } \\
\text { rBBI } \\
(\geq 0.85)\end{array}$ & Total & $\begin{array}{l}\text { Low } \\
\text { rBBI } \\
(<0.85)\end{array}$ & $\begin{array}{l}\text { High } \\
\text { rBBI } \\
(\geq 0.85)\end{array}$ \\
\hline$N(\%)$ & $\begin{array}{l}10,556 \\
(100)\end{array}$ & $\begin{array}{l}7889 \\
(75)\end{array}$ & $\begin{array}{l}2667 \\
(25)\end{array}$ & $\begin{array}{l}1959 \\
(100)\end{array}$ & $\begin{array}{l}1423 \\
(73)\end{array}$ & $\begin{array}{l}536 \\
(27)\end{array}$ & $\begin{array}{l}7034 \\
(100)\end{array}$ & $\begin{array}{l}5285 \\
(75)\end{array}$ & $\begin{array}{l}1749 \\
(25)\end{array}$ & $\begin{array}{l}1563 \\
(100)\end{array}$ & $\begin{array}{l}1181 \\
(76)\end{array}$ & $\begin{array}{l}382 \\
(24)\end{array}$ \\
\hline $\begin{array}{l}\text { Visits, mean } \\
\text { (SD) }\end{array}$ & $\begin{array}{l}9.3 \\
(6.1)\end{array}$ & $\begin{array}{l}8.8 \\
(5.8)\end{array}$ & $\begin{array}{l}10.7 \\
(6.9)\end{array}$ & $\begin{array}{l}7.5 \\
(4.5)\end{array}$ & $\begin{array}{l}7.3 \\
(4.4)\end{array}$ & $\begin{array}{l}8.1 \\
(4.7)\end{array}$ & $\begin{array}{l}9.3 \\
(6.0)\end{array}$ & $\begin{array}{l}8.7 \\
(5.5)\end{array}$ & $\begin{array}{l}10.9 \\
(7.0)\end{array}$ & $\begin{array}{l}11.9 \\
(7.5)\end{array}$ & $\begin{array}{l}11.2 \\
(7.3)\end{array}$ & $\begin{array}{l}13.8 \\
(7.9)\end{array}$ \\
\hline $\begin{array}{l}\text { Providers, mean } \\
\text { (SD) }\end{array}$ & $\begin{array}{l}4.2 \\
(2.3)\end{array}$ & $\begin{array}{l}3.5 \\
(1.7)\end{array}$ & $\begin{array}{l}6.3 \\
(2.4)\end{array}$ & $\begin{array}{l}3.9 \\
(1.8)\end{array}$ & $\begin{array}{l}3.2 \\
(1.4)\end{array}$ & $\begin{array}{l}5.5 \\
(1.8)\end{array}$ & $\begin{array}{l}4.2 \\
(2.2)\end{array}$ & $\begin{array}{l}3.5 \\
(1.6)\end{array}$ & $\begin{array}{l}6.3 \\
(2.4)\end{array}$ & $\begin{array}{l}4.8 \\
(2.7)\end{array}$ & $\begin{array}{l}3.9 \\
(2.1)\end{array}$ & $\begin{array}{l}7.4 \\
(2.8)\end{array}$ \\
\hline $\begin{array}{l}\text { Percent of visits } \\
\text { with the most } \\
\text { frequently seen } \\
\text { provider, mean, } \\
\text { (SD) }\end{array}$ & $51(20)$ & $58(18)$ & $29(7)$ & $\begin{array}{l}50 \\
(19)\end{array}$ & $58(17)$ & $30(7)$ & $\begin{array}{l}51 \\
(20)\end{array}$ & $58(18)$ & $29(7)$ & $\begin{array}{l}51 \\
(21)\end{array}$ & $58(19)$ & $28(7)$ \\
\hline $\begin{array}{l}\text { Fragmentation } \\
\text { score, rBBI } \\
\text { (SD) }\end{array}$ & $\begin{array}{l}0.70 \\
(0.23)\end{array}$ & $\begin{array}{l}0.63 \\
(0.22)\end{array}$ & $\begin{array}{l}0.91 \\
(0.04)\end{array}$ & $\begin{array}{l}0.72 \\
(0.22)\end{array}$ & $\begin{array}{l}0.64 \\
(0.21)\end{array}$ & $\begin{array}{l}0.92 \\
(0.05)\end{array}$ & $\begin{array}{l}0.70 \\
(0.23)\end{array}$ & $\begin{array}{l}0.63 \\
(0.22)\end{array}$ & $\begin{array}{l}0.91 \\
(0.04)\end{array}$ & $\begin{array}{l}0.68 \\
(0.24)\end{array}$ & $\begin{array}{l}0.61 \\
(0.23)\end{array}$ & $\begin{array}{l}0.90 \\
(0.04)\end{array}$ \\
\hline
\end{tabular}

Key: $r B B I=$ reversed Bice-Boxerman Index (BBI), equivalent to $1-B B I$, such that higher scores indicate more fragmentation. ${ }^{19}$ All comparisons of low vs. high rBBI, overall and within self-rated health subgroup, are statistically significant $(p<0.001)$. To be included in the analysis, a participant had to have $\geq 4$ ambulatory visits in his or her first year of observation

SD standard deviation

unadjusted rate of 8.8 events per 1000 person-years. Those with worse self-rated health at baseline had more CHD events: $4.0 \%$ of those with excellent self-rated health, $5.4 \%$ of those with very good/good self-rated health, and $6.9 \%$ of those with fair/poor self-rated health had a CHD event $(p=0.001)$. Adjusted incidence rates are shown in Figure 1.

Overall, the adjusted hazard ratio (HR) for the association between fragmentation and CHD events was 1.14 (95\% confidence interval (CI) 0.92, 1.39) (Table 4, Appendix 6). However, there was an interaction between fragmentation and self- rated health (Wald test: $p<0.01$ ). Among those with excellent self-rated health, there was no association between fragmentation and CHD events (adjusted HR 0.91; 95\% CI 0.53, 1.57; $p=0.74)$. Among those with very good or good self-rated health, high fragmentation was associated with an increased hazard of CHD events (adjusted HR 1.35; 95\% CI 1.06, 1.73; $p=0.01$ ), compared to low fragmentation. Among those with fair or poor self-rated health, high fragmentation was associated with a trend toward a decreased hazard of CHD events (adjusted HR 0.54; 95\% CI 0.29, 1.01; $p=0.052$ ).

Table 3 Incident Rates of Acute Coronary Heart Disease Event, Stratified by Self-Rated General Health and by Fragmentation Status

\begin{tabular}{|c|c|c|c|c|}
\hline & \multirow[t]{2}{*}{ Overall } & \multicolumn{3}{|c|}{ Self-rated general health } \\
\hline & & Excellent & Very good or good & Fair or poor \\
\hline \multicolumn{5}{|l|}{ Sample sizes and observation time } \\
\hline$N(\%)$ & $10,556(100)$ & $1959(19)$ & $7034(66)$ & $1563(15)$ \\
\hline Range of observation time & 4 days to 11.8 years & 4 days to 11.8 years & 7 days to 11.8 years & 7 days to 11.8 years \\
\hline Median observation time, years (IQR) & $5.5(2.8,9.1)$ & $6.4(3,2,9.9)$ & $5.7(3.0,9.3)$ & $4.0(2.0,7.5)$ \\
\hline \multicolumn{5}{|l|}{ Event counts and rates } \\
\hline \multicolumn{5}{|l|}{ Total } \\
\hline Observed number of events (\% persons) & $569(5.4 \%)$ & $78(4.0 \%)$ & $383(5.4 \%)$ & $108(6.9 \%)$ \\
\hline Observed number of person-years & 63,130 & 12,712 & 42,761 & 7656 \\
\hline Unadjusted rate per 1000 person-years & 9.0 & 6.1 & 8.9 & 14.1 \\
\hline Adjusted rate per 1000 person-years & 9.1 & 6.6 & 9.0 & 14.2 \\
\hline \multicolumn{5}{|l|}{ Low fragmentation } \\
\hline Observed number of events ( $\%$ persons) & $430(5.5 \%)$ & $65(4.6 \%)$ & $279(5.3 \%)$ & $86(7.3 \%)$ \\
\hline Observed number of person-years & 43,363 & 8459 & 29,484 & 5419 \\
\hline Unadjusted rate per 1000 person-years & 8.7 & 6.3 & 8.2 & 15.3 \\
\hline Adjusted rate per 1000 person-years & 8.7 & 6.8 & 8.0 & 16.1 \\
\hline \multicolumn{5}{|l|}{ High fragmentation } \\
\hline Observed number of events (\% persons) & $139(5.2 \%)$ & $13(2.4 \%)$ & $104(6.0 \%)$ & $22(5.8 \%)$ \\
\hline Observed number of person-years & 19,767 & 4253 & 13,277 & 2237 \\
\hline Unadjusted rate per 1000 person-years & 9.7 & 5.9 & 10.6 & 11.2 \\
\hline Adjusted rate per 1000 person-years & 10.0 & 6.3 & 11.1 & 9.1 \\
\hline
\end{tabular}

Adjusted rates were derived from Poisson models that adjusted for age, gender, race, marital status, educational attainment, income, region, hypertension, hyperlipidemia, diabetes, body mass index, albumin-to-creatinine ratio, C-reactive protein, number of medications, smoking, alcohol use, and lack of social support. Fragmentation status is a time-varying exposure based on the reversed Bice-Boxerman Index (low $<0.85$, high $\geq 0.85$ ). See "METHODS" for more details 


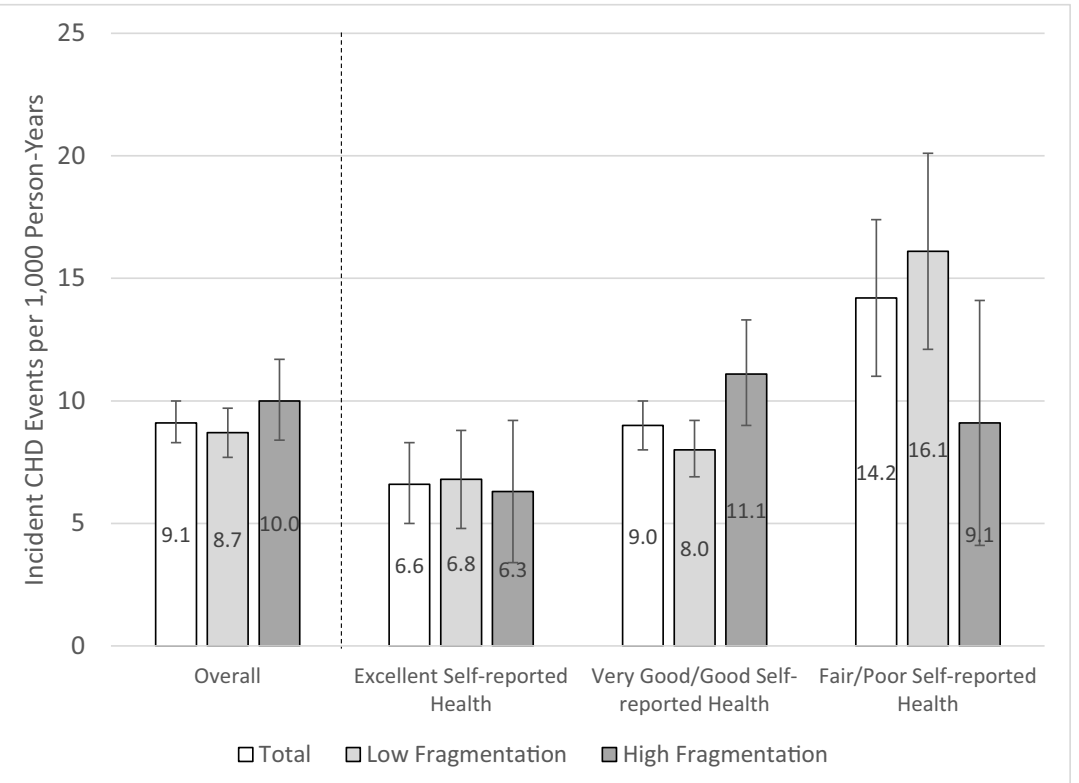

Figure 1 Absolute adjusted rates of incident coronary heart disease (CHD) events, stratified by healthcare fragmentation status and self-rated general health. Adjusted rates were derived from Poisson models that adjusted for age, gender, race, marital status, educational attainment, income, region, hypertension, hyperlipidemia, diabetes, body mass index, albumin-to-creatinine ratio, C-reactive protein, number of medications, smoking, alcohol use, and lack of social support. Fragmentation status is a time-varying exposure based on the reversed BiceBoxerman Index (low $<\mathbf{0 . 8 5}$, high $\geq \mathbf{0 . 8 5}$ ). See "METHODS" for more details.

Results persisted in the sensitivity analyses that used the base case set of covariates with multiple imputation, the 6month outcome period, all covariates with a complete case approach, and all covariates with a multiple imputation approach (Appendix 7). In the sensitivity analysis that excluded participants $<65$ years old at baseline, the results for excellent and very good/good self-rated health persisted, and the results for fair/poor self-rated health reached statistical significance (adjusted HR 0.42; 95\% CI 0.20, 0.91). In the sensitivity analysis stratifying self-rated health into 5 groups, confidence intervals were wider and high fragmentation was associated with a decreased hazard of CHD events in the fair self-rated health group (adjusted HR 0.43; 95\% CI 0.20, 0.92, Appendix 8).

\section{DISCUSSION}

In this 12-year study of 10,556 Medicare beneficiaries from the REGARDS cohort, the association between fragmented ambulatory care and incident CHD events varied with health status. Among those with very good or good self-rated health, having highly fragmented care was associated with an increased adjusted hazard of a CHD event in the 3 months following the exposure. Among those with fair or poor selfrated health, having highly fragmented care was associated with a decreased adjusted hazard a CHD event over the same time period. Among those with excellent self-rated health, there was no association between fragmentation and CHD events. The ambulatory care patterns underlying high vs. low

Table 4 Association Between Healthcare Fragmentation and Incident Coronary Heart Disease (CHD) Events, Overall and Stratified by SelfRated General Health $(N=10,556)$

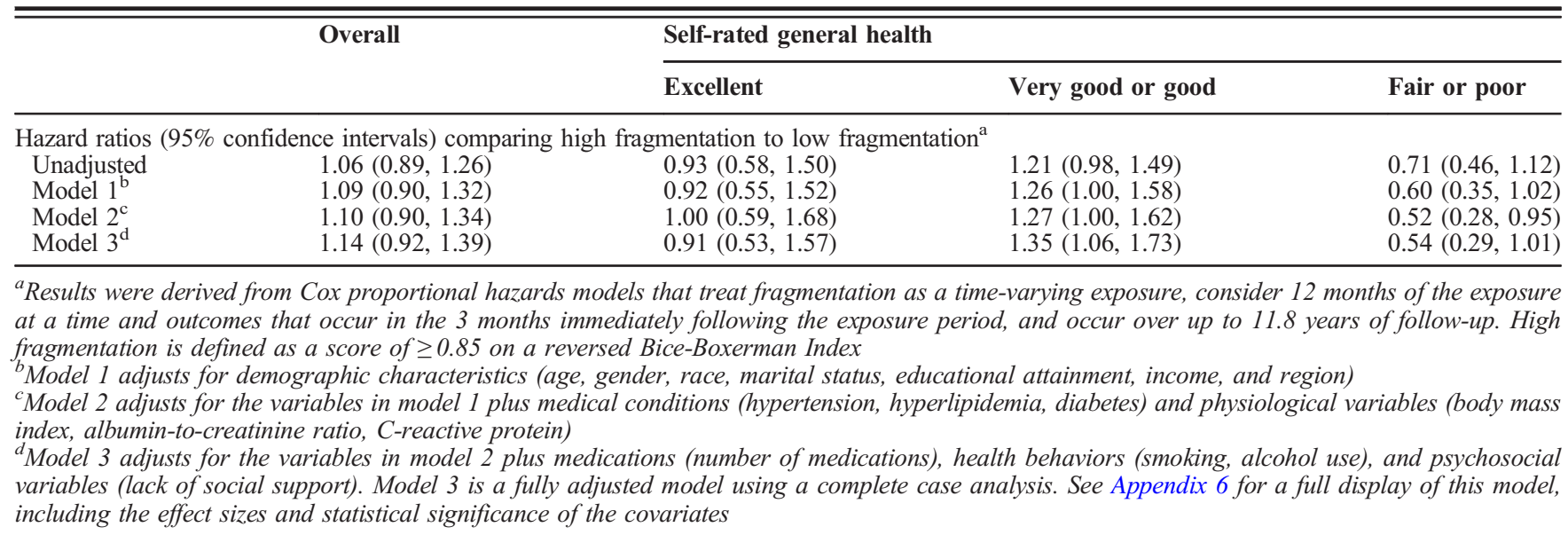


fragmentation were clinically and statistically different from each other: those with high fragmentation had an average of 11 visits to 6 providers per year, with the most frequently seen provider accounting for $29 \%$ of the visits, whereas those with low fragmentation had an average of 9 visits to 4 providers per year, with the most frequently seen provider accounting for $58 \%$ of visits.

These results are concordant with our previous study of Medicare beneficiaries in New York State, which found that healthcare fragmentation was not associated with hospitalizations among those with 0 chronic conditions, was associated with an increased hazard of hospitalization among those with 1-4 chronic conditions, and was associated with a decreased hazard of hospitalization among those with $\geq 5$ chronic conditions. ${ }^{12}$ Other studies of fragmentation have adjusted for burden of illness (rather than stratify), precluding additional comparisons. ${ }^{6,7,10}$

The exact mechanisms by which fragmentation could increase or decrease cardiac risk, depending on health status, are not clear. On the one hand, sicker patients may require more providers, ${ }^{1}$ and providers may make more of an effort to coordinate care for sick patients, ${ }^{39}$ thereby ameliorating the risk of gaps in communication. Sicker patients may also have access to more ancillary providers like care managers, who may facilitate care coordination. ${ }^{40}$ On the other hand, for patients with a moderate burden of illness, more fragmented care may lead to worse control of cardiac risk factors, through less aggressive management of those risk factors or discontinuation of beneficial medications. ${ }^{41-44}$ Multiple providers may also unknowingly prescribe drugs that interact, exacerbating cardiac risk factors. ${ }^{45-47}$ More work is needed to distinguish between beneficial and deleterious care fragmentation.

Strengths of this study include the national sampling frame, large sample size, long time horizon, homogeneity of insurance benefits across study participants through Medicare, use of a previously validated measure of fragmentation, treatment of fragmentation as a time-varying exposure, adjudicated CHD events, and adjustment for clinically detailed potential confounders.

This study has several limitations. First, it is observational; we cannot rule out residual confounding or infer causation. Second, we did not have data on cardiac risk factor control over time, so we cannot directly test the hypothesized mechanisms above. Third, this study did not measure communication between providers, so the presence of fragmentation cannot be interpreted as the definite absence of communication. Fourth, self-rated health was measured at baseline and may change over time. However, self-rated health at baseline was a significant predictor of CHD events. Fifth, we were not able to account for whether physicians were in the same practice; if physicians practicing together had access to the same medical records, buffering potential harm from fragmentation, this would have biased our study toward the null.

In conclusion, among Medicare beneficiaries with very good or good self-rated health (which was two-thirds of the sample), highly fragmented ambulatory care was associated with an independent increase in the short-term risk of an incident CHD event. More research is needed to determine exactly how fragmentation contributed to this risk and to determine whether interventions are needed to reduce unnecessary fragmentation of care.

\section{Acknowledgments:}

The authors thank Wesley Jacobsson, BSc, for his assistance with the literature review. The authors thank the other investigators, the staff, and the participants of the REGARDS study for their valuable contributions. A full list of participating REGARDS investigators and institutions can be found at http://www.regardsstudy.org .

Access to Data: Dr. Kern, Ms. Rajan, and Ms. Ringel had full access to the study data and take responsibility for the integrity of the analysis.

Corresponding Author: Lisa M. Kern, MD, MPH; Weill Cornell Medicine New York, NY, USA (e-mail: lmk2003@med.cornell.edu).

Author Contributions Study concept and design: Kern, Muntner, Casalino, Pesko, and Safford

Acquisition of data: Kern, Muntner, and Safford

Analysis and interpretation of the data: Kern, Rajan, Ringel, Colantonio, Muntner, Casalino, Pesko, Reshetnyak, Pinheiro, and Safford

Drafting of the manuscript: Kern

Critical revision of the manuscript for important intellectual content: Kern, Rajan, Ringel, Colantonio, Muntner, Casalino, Pesko, Reshetnyak, Pinheiro, and Safford

Statistical analysis: Rajan and Ringel

Obtained funding: Kern, Muntner, and Safford

Administrative, technical, or material support: Kern, Rajan, Ringel, Colantonio, Muntner, and Safford

Study supervision: Kern, Muntner, and Safford

Funding The REGARDS study is co-funded by the National Institute of Neurological Disorders and Stroke; the National Institute on Aging and the National Institutes of Health, Department of Health and Human Services (UO1 NS041588). Adjudication for CHD events for REGARDS was funded by the National Heart, Lung, and Blood Institute (RO1 HL080477). The ancillary study on healthcare fragmentation and cardiovascular outcomes was funded by the National Heart, Lung, and Blood Institute (RO1 HL135199). The funding agencies played no role in the design or conduct of the study, and no role in data management, data analysis, interpretation of data, or preparation of the manuscript. The REGARDS Executive Committee reviewed and approved this manuscript prior to submission, ensuring adherence to standards for describing the REGARDS study.

\section{Compliance with Ethical Standards:}

Conflict of Interest: The authors have completed and submitted the ICMJE Form for Disclosure of Potential Conflicts of Interest.

Dr. Kern is a consultant to Mathematica, Inc.

Ms. Rajan receives fees from the Veterans Biomedical Research Institute.

Dr. Safford receives grant funds from Amgen, Inc.

The other co-authors reported no conflicts

\section{REFERENCES}

1. Pham HH, Schrag D, O'Malley AS, Wu B, Bach PB. Care patterns in Medicare and their implications for pay for performance. N Engl J Med 2007;356:1130-9. 
2. O'Malley AS, Reschovsky JD. Referral and consultation communication between primary care and specialist physicians: finding common ground. Arch Intern Med 2011;171:56-65.

3. Pham HH, O'Malley AS, Bach PB, Saiontz-Martinez C, Schrag D. Primary care physicians' links to other physicians through Medicare patients: the scope of care coordination. Ann Intern Med 2009; 150:236-42.

4. Smith PC, Araya-Guerra R, Bublitz C, et al. Missing clinical information during primary care visits. JAMA 2005;293:565-71.

5. Kern LM, Seirup JK, Casalino LP, Safford MM. Healthcare fragmentation and the frequency of radiology and other diagnostic tests: a crosssectional study. J Gen Intern Med 2017;32:175-81.

6. Romano MJ, Segal JB, Pollack CE. The Association Between Continuity of Care and the Overuse of Medical Procedures. JAMA Intern Med 2015; 175: 1148-54

7. Hussey PS, Schneider EC, Rudin RS, Fox DS, Lai J, Pollack CE Continuity and the costs of care for chronic disease. JAMA Intern Med 2014;174:742-8.

8. Katz DA, McCoy KD, Vaughan-Sarrazin MS. Does Greater Continuity of Veterans Administration Primary Care Reduce Emergency Department Visits and Hospitalization in Older Veterans? J Am Geriatr Soc 2015;63:2510-8.

9. Liu CW, Einstadter D, Cebul RD. Care fragmentation and emergency department use among complex patients with diabetes. Am J Manag Care 2010;16:413-20.

10. Nyweide DJ, Anthony DL, Bynum JP, et al. Continuity of care and the risk of preventable hospitalization in older adults. JAMA Intern Med 2013;173:1879-85.

11. van Walraven $\mathbf{C}$, Oake $\mathbf{N}$, Jennings A, Forster AJ. The association between continuity of care and outcomes: a systematic and critical review. J Eval Clin Pract 2010;16:947-56.

12. Kern LM, Seirup J, Rajan M, Jawahar R, Stuard SS. Fragmented ambulatory care and subsequent healthcare utilization among Medicare beneficiaries. Am J Manag Care 2018;24:e278-e84.

13. Benjamin EJ, Virani SS, Callaway CW, et al. Heart Disease and Stroke Statistics-2018 Update: A Report From the American Heart Association. Circulation 2018;137:e67-e492.

14. Linzer M, Myerburg RJ, Kutner JS, et al. Exploring the generalistsubspecialist interface in internal medicine. Am J Med 2006; 119:528-37.

15. Howard VJ, Cushman M, Pulley $\mathbf{L}$, et al. The reasons for geographic and racial differences in stroke study: objectives and design. Neuroepidemiology 2005;25:135-43.

16. Safford MM, Brown TM, Muntner PM, et al. Association of race and sex with risk of incident acute coronary heart disease events. JAMA 2012;308:1768-74.

17. Xie F, Colantonio LD, Curtis JR, et al. Linkage of a populaton-based cohort with primary data collection to Medicare claims: The REasons for Geographic and Racial Differences in Stroke (REGARDS) study. Am J Epidemiol 2016;184:532-44.

18. National Committee for Quality Assurance. HEDIS Volume 2: Technical Specifications, 2015. (Accessed May 22, 2020, at http://www.ncqa.org/ HEDISQualityMeasurement/HEDISMeasures/HEDIS2015.aspx.)

19. Bice TW, Boxerman SB. A quantitative measure of continuity of care. Med Care 1977; 15:347-9.

20. Jee SH, Cabana MD. Indices for continuity of care: a systematic review of the literature. Med Care Res Rev 2006;63:158-88.

21. Luepker RV, Apple FS, Christenson RH, et al. Case definitions for acute coronary heart disease in epidemiology and clinical research studies: a statement from the AHA Council on Epidemiology and Prevention; AHA Statistics Committee; World Heart Federation Council on Epidemiology and Prevention; the European Society of Cardiology Working Group on Epidemiology and Prevention; Centers for Disease Control and Prevention; and the National Heart, Lung, and Blood Institute. Circulation 2003; 108:2543-9.

22. Thygesen $\mathbf{K}$, Alpert JS, Jaffe AS, et al. Third universal definition of myocardial infarction. Circulation 2012;126:2020-35.

23. U.S. Department of Agriculture. Rural-Urban Commuting Area Codes. (Accessed May 22, 2020, at https://www.ers.usda.gov/data-products/ rural-urban-commuting-area-codes.aspx.)

24. Gunzerath L, Faden V, Zakhari S, Warren K. National Institute on
Alcohol Abuse and Alcoholism report on moderate drinking. Alcohol Clin Exp Res 2004;28:829-47.

25. Radloff LS. The CES-D scale: A self-report depression scale for research in the general population. Applied Psychological Measurement 1977; 1:385-401

26. Levey AS, Stevens LA, Schmid CH, et al. A new equation to estimate glomerular filtration rate. Ann Intern Med 2009; 150:604-12.

27. National Kidney Foundation. Albumin-to-creatinine ratio (ACR) (Accessed May 22, 2020 at https://www.kidney.org/kidneydisease/ siemens_hcp_acr.)

28. DeSalvo KB, Bloser N, Reynolds K, He J, Muntner P. Mortality prediction with a single general self-rated health question. A metaanalysis. J Gen Intern Med 2006;21:267-75

29. DeSalvo KB, Fan VS, McDonell MB, Fihn SD. Predicting mortality and healthcare utilization with a single question. Health Serv Res 2005;40: 1234-46.

30. DeSalvo KB, Fisher WP, Tran K, Bloser N, Merrill W, Peabody J. Assessing measurement properties of two single-item general health measures. Qual Life Res 2006;15:191-201.

31. Ware J, Jr., Kosinski M, Keller SD. A 12-Item Short-Form Health Survey: construction of scales and preliminary tests of reliability and validity. Med Care 1996;34:220-33.

32. U.S. Department of Health and Human Services. Who is eligible for Medicare? 2020. (Accessed May 22, 2020, at https://www.hhs.gov/ answers/medicare-and-medicaid/who-is-elibible-for-medicare/index. html.)

33. Kern LM, Seirup J, Rajan M, Jawahar R, Stuard SS. Fragmented ambulatory care and subsequent emergency department visits and hospital admissions among Medicaid beneficiaries. Am J Manag Care 2019;25:107-12.

34. Chang HG, Lininger LL, Doyle JT, Maccubbin PA, Rothenberg RB. Application of the Cox model as a predictor of relative risk of coronary heart disease in the Albany Study. Stat Med 1990;9:287-92.

35. Fisher LD, Lin DY. Time-dependent covariates in the Cox proportionalhazards regression model. Annu Rev Public Health 1999;20:145-57.

36. Fleming TR, Harrington DP. Counting process and survival analysis. Hoboken, NJ: John Wiley \& Sons, Inc.; 2005.

37. Rubin DB, Schenker N. Multiple imputation in health-care databases: an overview and some applications. Stat Med 1991;10:585-98.

38. Howard VJ, Kleindorfer DO, Judd SE, et al. Disparities in stroke incidence contributing to disparities in stroke mortality. Ann Neurol 2011;69:619-27.

39. Hays RD, Mallett JS, Haas A, et al. Associations of CAHPS Composites With Global Ratings of the Doctor Vary by Medicare Beneficiaries' Health Status. Med Care 2018;56:736-9.

40. Haime V, Hong $\mathbf{C}$, Mandel L, et al. Clinician considerations when selecting high-risk patients for care management. Am J Manag Care 2015;21:e576-82.

41. Lustman A, Comaneshter D, Vinker S. Interpersonal continuity of care and type two diabetes. Prim Care Diabetes 2016;10:165-70.

42. Maciejewski ML, Hammill BG, Bayliss EA, et al. Prescriber Continuity and Disease Control of Older Adults. Med Care 2017;55:405-10.

43. Parchman ML, Pugh JA, Noel PH, Larme AC. Continuity of care, selfmanagement behaviors, and glucose control in patients with type 2 diabetes. Med Care 2002;40:137-44.

44. Younge R, Jani B, Rosenthal D, Lin SX. Does continuity of care have an effect on diabetes quality measures in a teaching practice in an urban underserved community? J Health Care Poor Underserved 2012;23:1558-65.

45. Elliott WJ. Drug interactions and drugs that affect blood pressure. Journal of Clinical Hypertension 2006;8:731-7.

46. Guo JY, Chou YJ, Pu C. Effect of continuity of care on drug-drug interactions. Med Care 2017;55:744-51.

47. May M, Schindler C. Clinically and pharmacologically relevant interactions of antidiabetic drugs. Ther Adv Endocrinol Metab 2016;7:69-83.

Publisher's Note: Springer Nature remains neutral with regard to jurisdictional claims in published maps and institutional affiliations. 